\title{
A Lean Approach to Evaluating Prescribing Errors in Medication Reconciliation
}

\author{
Yudha PUTRA ${ }^{\mathrm{a}}$, Maryati Mohd. YUSOF ${ }^{\mathrm{a}, 1}$ \\ ${ }^{a}$ Faculty of Info. Sc. and Technology, Universiti Kebangsaan Malaysia, Malaysia
}

\begin{abstract}
We evaluated medication reconciliation processes of a qualitative case study at a 1000-bed public hospital. Lean tools were applied to identify factors contributing to prescribing errors and propose process improvement. Errors were attributed to the prescriber's skills, high workload, staff shortage, poor user attitude and rigid system function. Continuous evaluation of medication reconciliation efficiency is imperative to identify and mitigate errors and increase patient safety.
\end{abstract}

Keywords: evaluation, Lean, error, medication reconciliation, patient safety

\section{Introduction}

Medication reconciliation (MR) is commonly used for reducing medication errors by analysing the most accurate list of patient medications [1] to provide the most appropriate treatment for patients [2]. MR can benefit from quality improvement methods such as Lean, which focuses on the systematic elimination of waste in processes through synergistic practices [2]. Lean tools such as A3, value stream mapping (VSM), and 5 Whys can be used to identify the root cause of a problem. A3 employs a reporting tool to summarise the definition, scope, discovery process, findings, proposed action steps and results from the problem analysis. The paper reports MR process evaluation related to technology-induced prescribing errors (PE) in clinical practices.

\section{Methods}

We conducted a summative case study evaluation at a 1000-bed public specialist hospital. We obtained ethical approval to interview 10 informants, observe the process and analyse document. We analysed the results using narrative analysis and Lean tools.

\section{Results}

We analysed PE related to computerised physician order entry (CPOE) using A3 report: a. Over 600 miss PE incidents related to medication name/ dose/frequency were reported monthly (1-2 PE reach patients yearly).

\footnotetext{
${ }^{1}$ Corresponding Author. Maryati.Yusof@ukm.edu.my
} 
b. Current Conditions: During ward rounds, physicians prescribe the patient medication in the bed head ticket manual of his/her file to be entered by trainees after the rounds.

c. Problem Analysis: PE are usually committed by trainees during CPOE data entry. During ward rounds, some physicians gabbled, making it difficult for trainees to comprehend the drug name; some even have to guess the name due to their lack of therapeutic knowledge. If a trainee commits a prescribing error and he/she only realised it after submitting the prescription, he/she needs to create a new prescription by reentering the overall patient's medication as the edit or undo button is disabled in the CPOE. Prescriptions need to be entered repeatedly because the patient may have several drug prescriptions, leading to prescriber and pharmacists' confusion and errors. The PE is also visualised using VSM and analysed using the 5 Whys technique as follows:

High prescribing error rates:

- Why? Trainees enter wrong medication information (name/dose/frequency) in the CPOE

○ Why? Misunderstanding/confusion with physicians' verbal prescription

- Why? Guessing unclear medication information

- Why? Lack of knowledge/experience

- Why? Pharmacists overlook prescribing errors

- Why? Shortage of pharmacists to check all prescriptions

- Why? The tedious task of re-entering all patient medications

$\circ \quad$ Why? No edit or undo function to change a submitted prescription

- Why? Physicians use the copy-paste function from previous prescriptions

○ Why? Physicians are in a hurry and do not recheck the prescription

\section{Discussion and Conclusion}

Negative attitudes, lack of skill and knowledge in system and drugs, and lack of diligence amongst trainees and physicians in prescribing medication add workload and time pressure in MR. These are consistent with similar studies that identified various factors including therapeutic training, drug knowledge and experience, lack of prescribing skills and training, communication failures and heavy workload [1,3]. The A3 report aids in analysing problems and root causes and identifying optimum solutions to improve MR in reducing PE and improving patient safety. The problem analysis methods and root causes of this study may apply to other settings with similar contextual issues.

\section{Acknowledgement}

The study is sponsored by Ministry of Higher Learning Malaysia (FRGS/1/2018/ICT04/UKM/02/5) and the Sumitomo Foundation Grant.

\section{References}

[1] Manias E, Kusljic S, Wu A. Interventions to reduce medication errors in adult medical and surgical settings: a systematic review, Ther Adv Drug Saf. 2020;11:1-29.

[2] Putra Y, Yusof MM. A review of technology-induced error and waste in medication reconciliation, in: Proceedings of the Int Conf Elect Eng Inform; 2015 Aug 10-11;Bali IEEE, p. 716-719.

[3] Slight SP, Howard R, Ghaleb M, Barber N, Franklin BD, Avery AJ. The causes of prescribing errors in English general practices: a qualitative study, Br J Gen Pract 2013;63:e713-720. 